\section{Yasmina Laouar} Christophe Viret

\section{ADRESSE}

Y. Laouar, C. Viret : Section of Immunobiology, Yale University School of Medicine, 333 Cedar street, FMB 402, New Haven, CT 06520-8011, États-Unis.

$m / s n^{\circ} 12$, vol. 15 , décembre 99

\title{
Développement intrathymique des lymphocytes $T$ : rôle des peptides du soi dans le processus de sélection positive
}

Au cours du développement des lymphocytes $\mathrm{T} \alpha \beta$, le processus de sélection positive requiert l'interaction du récepteur de l'antigène (TCR) avec les molécules du complexe majeur d'histocompatibilité $(\mathrm{CMH})$ exprimées à la surface des cellules épithéliales du cortex thymique. On s'est longtemps demandé si l'interaction TCR-CMH est intrinsèquement suffisante ou si les peptides du soi complexés aux molécules du CMH remplissent un rôle particulier lors de la sélection positive. L'utilisation d'animaux génétiquement modifiés, présentant des altérations des processus d'apprêtement et/ou de présentation de l'antigène a permis de montrer que la diversité des peptides du soi présentés par les molécules du CMH a un impact direct sur l'efficacité du développement des lymphocytes $\mathrm{CD}^{+}$et $\mathrm{CD}^{+}$. L'ensemble de ces résultats expérimentaux indique que le développement intrathymique des lymphocytes $\mathbf{T} \alpha \beta$, et par conséquent l'élaboration du répertoire $\mathbf{T}$ fonctionnel, est fondée sur la reconnaissance des peptides du soi au cours du processus de sélection positive.

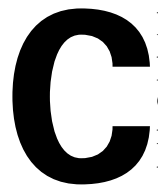

hez les vertébrés, les lymphocytes $\mathrm{T}$ constituent un compartiment cellulaire indispensable au développement d'une réponse immunitaire spécifique efficace lors des processus infectieux. Les lymphocytes $\mathrm{T}$, au sens large, regroupent plusieurs types de populations qui diffèrent par leur caractéristiques phénotypiques et fonctionnelles. Les lymphocytes $\mathrm{T} \alpha \beta$ qui se développent $\mathrm{au}$ sein du thymus sont dits "classiques» et représentent la population majoritaire et la mieux étudiée. Au terme de leur maturation intrathymique, les thymocytes ressemblent aux lymphocytes $\mathrm{T}$ périphériques; ils expriment fortement, selon une distribution clonale, un récepteur de l'antigène (TCR) constitué des glycoprotéines $\alpha$ et $\beta$ ainsi que le co-récep- 
teur CD4 ou CD8 qui définit les précurseurs des lymphocytes $\mathrm{T}$ auxiliaires $\mathrm{CD}^{+} \mathrm{CD}^{-}$(sources de cytokines) et les précurseurs des lymphocytes $\mathrm{T}$ cytotoxiques $\mathrm{CD} 4^{-}$ $\mathrm{CD}^{+}$(figure 1).

Les gènes codant pour les chaînes $\alpha$ et $\beta$ du TCR ne préexistent pas au sein du génome, ils sont engendrés à un stade précoce du développement (mal dit, auteur pouvez-vous modifier ce début de phrase SVP) via un processus de réarrangement de segments géniques dits variable (V), de diversité (D), de jonction (J) et constant (C) qui sont dans une configuration dispersée au sein des locus $\alpha$ et $\beta$. Ce processus, connu sous le terme de recombinaison $\mathrm{V}(\mathrm{D}) \mathrm{J}$ [1], implique plusieurs protéines dont les produits des gènes $R A G-1$ et RAG-2 (recombination-activating genes) spécifiquement exprimés par les lymphocytes ainsi que des protéines ubiquitaires de réparation de l'ADN. A cette diversité de type combinatoire (la recombinaison aléatoire de segments géniques) se superpose une diversité de type jonctionnelle (retrait et/ou ajout aléatoire de nucléotides à la jonction des segments réarrangés). La diversité du répertoire $\mathrm{T}$ en est considérablement accrue (elle est approximativement de l'ordre de $10^{18}$ ). Le bénéfice de la diversité jonctionnelle a cependant un coût énorme. De par sa nature stochastique, le processus d'addition/retrait de résidus nucléotidiques aboutit, dans les deux tiers des cas, à l'interruption du cadre de lecture des gènes réarrangés. Ainsi, seul un tiers des réarrangements sont productifs, c'est-à-dire qu'ils permettent la synthèse d'une chaîne $\alpha$ ou $\beta$ fonctionnelle. Le développement des lymphocytes $\mathrm{T} \gamma \delta$ au sein du thymus est moins bien documenté et ne sera pas évoqué ici.

A la différence des immunoglobulines synthétisées par les lymphocytes B, capables d'interagir avec l'antigène sous sa forme native, le TCR des lymphocytes $T \alpha \beta$ reconnaît l'antigène sous la forme de court fragments peptidiques présentés par des glycoprotéines membranaires: les molécules du complexe majeur d'histocompatibilité (CMH) de classe I et II, respectivement selon que le TCR est associé à l'expression des co-récepteurs CD8 ou CD4 (figure 1). La reconnaissance de l'antigène par le TCR des lymphocytes

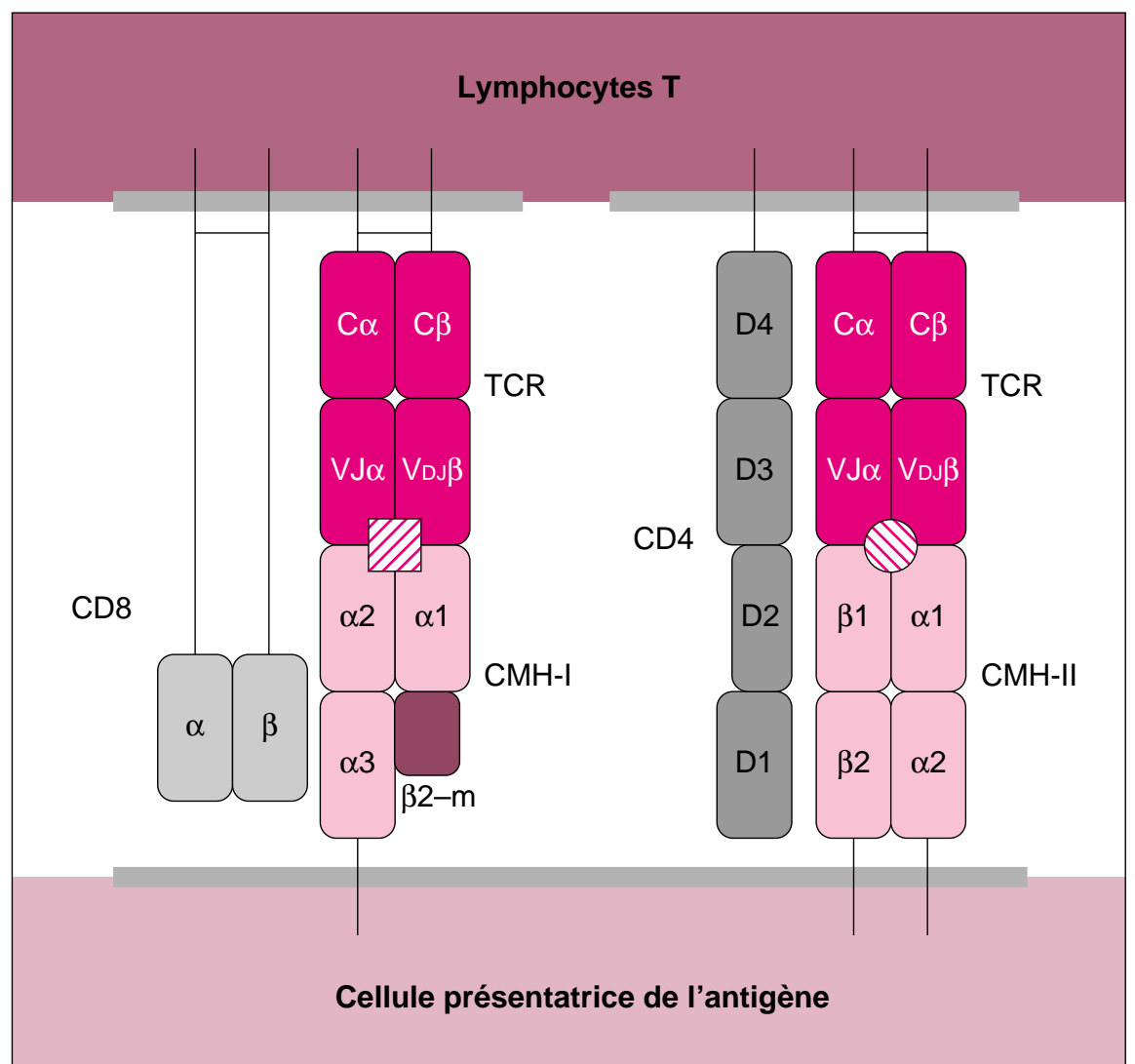

Figure 1. La reconnaissance de l'antigène par le TCR est restreinte par les molécules du CMH. Le récepteur de l'antigène (TCR), qui suit une distribution clonale, reconnaît des fragments peptidiques présentés par les molécules du $\mathrm{CMH}$. Plus précisément, cette interaction correspond à une co-reconnaissance puisque le TCR entre en contact à la fois avec des résidus acides aminés proéminents du peptide et des résidus polymorphiques des chaînes des molécules du CMH. Le TCR est un hétérodimère constitué de deux glycoprotéines transmembranaires $\alpha$ et $\beta$ dont la portion extracellulaire comporte deux domaines structuralement apparentés aux domaines variable et constant des chaînes d'immunoglobulines (lg). La spécificité du TCR est très largement déterminée par la séquence du domaine CDR3 qui relie les segments variable et constant et qui est un point de contact direct avec le peptide lors de l'interaction tri-moléculaire TCR-peptide-CMH. La reconnaissance du complexe peptide-CMH est grandement assistée par l'engagement du corécepteur (CD4 ou CD8) qui stabilise l'interaction tri-moléculaire et participe également au processus de l'activation des lymphocytes $T$ via le recrutement de la protéine kinase $p 56^{\text {lck. }}$. CD4 comprend quatre domaines de type lg. CD8 est un hétérodimère $\alpha \beta$ avec un seul domaine de type lg au sein de chacune des deux chaînes. Afin d'alléger le schéma, le module de transduction du signal associé au TCR (le complexe CD3) n'est pas représenté. Les ponts disulfures interchaînes sont représentés par un trait de liaison horizontal. Le peptide antigénique est représenté par la surface hachurée insérée au sommet des molécules du CMH (8-9 acides aminés pour le CMH l et 14-17 acides aminés pour le CMH II). TCR: récepteur de l'antigène des lymphocytes $T$; CMH: complexe majeur d'histocompatibilité ; CD4/CD8: corécepteurs $C D 4 / C D 8 ; V / D / J / C$ : segment variable/de diversité/de jonction/ constant; $\beta 2-$ $m$ : $\beta 2$-microglobuline.

$\mathrm{T} \alpha \beta$ classiques est dite restreinte par les molécules du complexe majeur d'histocompatibilité [2] $(\mathrm{m} / \mathrm{s}$ 1996, $\left.n^{\circ} 11, p .1316\right)$. En l'absence de protéines d'origine microbienne, les molécules du CMH demeurent exprimées à la surface mais sont complexées avec des peptides dérivés de protéines endogènes. En fait, l'expression membranaire stable de ces molé- 
cules est directement dépendante de leur association avec des peptides.

L'élaboration du répertoire du TCR des lymphocytes $\mathrm{T} \alpha \beta$ mûrs a lieu lors de leur développement intrathymique par une succession d'étapes sélectives (figure 2). Les événements les plus précoces conduisent à la production et à l'expression membranaire du TCR $\alpha \beta$. Cette étape permet de poursuivre la progression liéé au développement jusqu'au stade où les thymocytes sont exposés à une nouvelle sélection. Pour survivre, achever leur maturation et quitter l'environnement thymique, ils doivent satisfaire à une double exigence: leur TCR doit avoir une affinité minimale pour les complexes CMH-peptides exprimés dans le thymus mais cette affinité ne doit pas excéder un certain seuil. Cette double exigence est satisfaite grâce à des processus dits de sélection intrathymique positive et négative ayant tout deux pour origine l'interaction du TCR avec les molécules du CMH présentes dans l'environnement thymique. Par définition, la nature des peptides du soi est directement responsable de la sélection négative intrathymique qui est un processus majeur de la tolérance aux antigènes du soi. En ce qui concerne la sélection positive, la question de savoir si une interaction TCR$\mathrm{CMH}$ est seule en cause ou si les pep- tides du soi ont une fonction importante allant au-delà de leur propriété de stabilisation des molécules du CMH a suscité un intérêt croissant. Le rôle des peptides du soi dans l'élaboration du répertoire lymphocytaire $\mathrm{T} \alpha \beta$ a récemment été examiné dans des modèles in vivo s'attachant particulièrement à l'étude du développement des lymphocytes $\mathrm{T} \mathrm{CD}^{+}$. La plupart des études évoquées dans cet article utilisent des animaux génétiquement modifiés présentant des altérations des processus d'apprêtement et de présentation de l'antigène, nous allons donc très succinctement résumer les grands principes gouvernant ces processus.

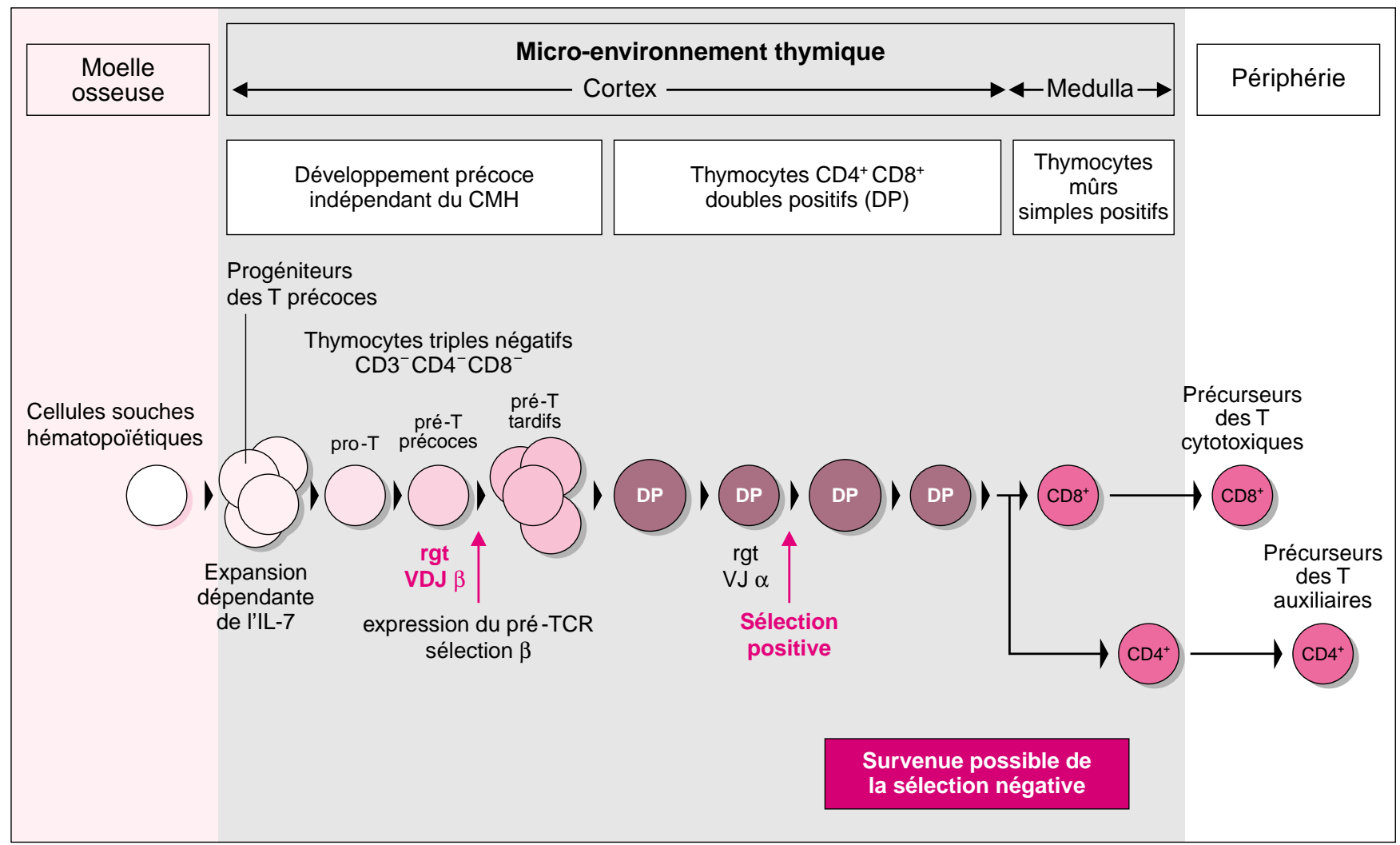

Figure 2. Représentation synoptique du développement intrathymique des lymphocytes T $\alpha \beta$. Les lymphocytes T $\alpha \beta$ sont issus des cellules souches hématopoiétiques qui colonisent le thymus. La phase précoce de développement est indépendante des molécules du $\mathrm{CMH}$. Les réarrangements sont en premier lieu déclenchés au niveau du locus $\beta$ (rgt.VDJ $\beta$ ). L'expression du pré-TCR constitué d'une chaîne $\beta$ et de la chaîne pT $\alpha$ permet la réception d'un signal antiapoptotique et la progression des cellules au stade de développement suivant (sélection $\beta$ ). La transition au stade $C D 4^{+} C D 8^{+}$(double positif) s'accompagne de réarrangement $V$-J au niveau du locus $\alpha$ (rgtVJ $\alpha$ ). En cas de réarrangement productif, un TCR $\alpha \beta$ se substitue au pré-TCR. Dès lors, le développement des thymocytes est subordonné aux interactions du TCR avec les complexes peptides-molécules du CMH exprimés à la surface des cellules stromales thymiques. L'intégration des signaux délivrés lors de l'interaction thymocytes/cellules stromales conduit à la sélection positive (cette phase est dépendante des cellules épithéliales corticales) et éventuellement, à la délétion des thymocytes (ou sélection négative) qui assure l'établissement de la tolérance aux antigènes du soi exprimés par les cellules d'origine hématopoïétique. Les thymocytes sélectionnés positivement achèvent leur maturation au sein de la médulla; ils deviennent $C D 4^{-} C D 8^{+}$ou $C D 4^{+} C D 8^{-}$et gagnent les organes lymphoïdes périphériques au sein desquels ils constituent respectivement les précurseurs des lymphocytes cytotoxiques $\left(C D 8^{+}\right)$et auxiliaires $\left(C D 4^{+}\right)$. 


\section{Les mécanismes de l'apprêtement et de la présentation de l'antigène}

Dans le cas des molécules de classe I du CMH, les complexes CMH-peptide sont assemblés au sein du réticulum endoplasmique (figure 3). Les fragments peptidiques résultant de la dégradation de protéines cytosoliques par des complexes protéolytiques multicatalytiques (le protéasome $20 \mathrm{~S}$ ainsi que d'autres structures protéolytiques) sont transférés activement dans la lumière du réticulum endoplasmique par des molécules membranaires de transport (TAP1 et TAP2) [3]. Dans un premier temps, les molécules de classe I, constituées d'une chaîne lourde polymorphe transmembranaire associée à une chaîne légère non polymorphe ( $\beta 2$-microglobuline ou $\beta 2-m)$, sont mises en contact avec les sous-unités TAP grâce à l'intervention de protéines chaperonnes (calnexine, calréticuline) et accessoires (tapasine). Au cours d'une seconde phase, les fragments peptidiques qui présentent les caractéristiques requises de taille et de structure, s'associent aux molécules de classe I. Cette liaison est à l'origine de la dissociation des complexes supramoléculaires; les molécules de classe I sont libérées et entament, au travers de l'appareil de Golgi, leur transport vers la membrane cellulaire (voir [4] pour une synthèse générale actualisée). Dans le cas des molécules de classe II du CMH, la situation est sensiblement différente (figure 4). Les chaînes $\alpha$ et $\beta$ des molécules de classe II s'associent pour former les hétérodimères $\alpha \beta$ au sein du réticulum. Un niveau supérieur de complexité est atteint lorsque trois hétérodimères s'associent à trois molécules de chaîne invariante (Ii) pour former des nonamères $(\alpha \beta)_{3} \mathrm{Ii}_{3}$. Ce niveau d'organisation est nécessaire pour que les molécules de classe II soient transférées dans l'appareil de Golgi. La portion cytoplasmique de Ii contient un motif de routage qui, à la sortie des vésicules golgiennes, dirige les molécules de classe II vers les compartiments de la voie endocytique (vraisemblablement par une entrée au niveau des endosomes pré- avec les peptides antigéniques ou endogènes. Par ailleurs, la présence de Ii, par l'occupation du site de liaison des peptides, prévient physiquement toute association peptidique prématurée jusqu'à ce que les compartiments endocytiques soient atteints. Ii est ensuite dégradée par plusieurs endoprotéases de la famille des cathepsines présentes dans les vésicules endocytiques. Cette dégradation, qui semble s'opérer de façon séquentielle, cause la dissociation des structures nonamériques. Les molécules de classe II ne sont plus finalement associées qu'à un court fragment de Ii (le peptide CLIP) au niveau de leur site de liaison des peptides. Dans les compartiments endocytiques, d'autres molécules interviennent pour aider au retrait du peptide CLIP et au chargement des peptides, notamment la molécule $\mathrm{H}$ 2M (elle aussi un hétérodimère $\alpha \beta$ dont les gènes sont localisés dans le locus du CMH) et les molécules H$2 \mathrm{O}$ qui règlent l'activité de $\mathrm{H}-2 \mathrm{M}$. Le transport des complexes stables $\mathrm{CMH}$ de classe II-peptide à la surface cellulaire implique les vésicules CIIV qui émergeraient des endosomes précoces (et peut-être tardifs) par un processus de bourgeonnement spécifique [5-7].

\section{Le développement précoce des lymphocytes $T \alpha \beta$ est indépendant des molécules du CMH}

Les précurseurs $\mathrm{T}$ les plus précoces expriment les molécules CD44, CD117 (c-kit), le récepteur de l'interleukine-7 (IL-7R) et CD24 (heat stable antigen), un marqueur d'immaturité lymphocytaire. Puis, l'induction de CD25 ainsi qu'une phase de prolifération induite par l'IL-7 (stade proLT) ont lieu (figure 2). Le stade suivant (pré-LT précoces) est associé à une réduction de l'expression de CD44 et de CD117, à l'induction de CD2 et au démarrage du réarrangement V-D-J au niveau du locus $\beta$. Cette étape marque la mise en route de la différenciation lymphocytaire T. Si ce réarrangement conduit à la synthèse d'une chaîne $\beta$ fonctionnelle, il permet l'expression à la surface du pré-TCR (stade pré-LT tardif) composé d'une chaîne $\beta$ associée à une glycoprotéine invariante, $\mathrm{pT} \alpha$
[8]. L'expression du pré-TCR correspond à une phase cruciale du développement; un signal de survie est délivré qui permet aux cellules d'accéder au stade CD4 $4^{+} \mathrm{CD}^{+}$(sélection $\beta$, voir [9] pour revue). L'expression du pré-TCR a pour conséquence de prévenir tout réarrangement au niveau du second locus $\beta$ (exclusion allélique $\beta$ ). Ce processus implique une protéine kinase spécifique de la lignée lymphocytaire $T$, la p $56^{\text {lck }}$. Simultanément, l'expression de CD25 disparaît, des réarrangements V-J sont déclenchés au niveau du locus $\alpha$ et l'expression des gènes $C D 8$ et $\mathrm{CD} 4$ est induite (les thymocytes prolifèrent et deviennent doublement positifs pour CD4 et CD8). Un TCR $\alpha \beta$ se substitue au pré-TCR, les thymocytes réduisent leur taille et cessent de proliférer. Le TCR $\alpha \beta$ va contrôler les événements suivants, notamment la transition $\mathrm{CD} 4^{+} \mathrm{CD}^{+} \rightarrow$ $\mathrm{CD}^{+} \mathrm{CD}^{-} / \mathrm{CD}^{-} \mathrm{CD}^{+}$. L'interaction du pré-TCR avec un ligand est théoriquement possible. Il a été montré que la transition contrôlée par le préTCR survient normalement chez les animaux déficients en molécules du CMH ou chez des mutants exprimant une chaîne $\beta$ transgénique dépourvue de son domaine variable [9] indiquant que s'il y a interaction, celle-ci n'implique pas les complexes peptide-CMH.

\section{La double sélection des lymphocytes $T \alpha \beta$ immatures}

Comme nous l'avons vu ci-dessus, les thymocytes immatures sont exposés à un double processus de sélection (les thymocytes sont alors au stade $\mathrm{CD} 4^{+} \mathrm{CD} 8^{+}$). Seules les cellules exprimant un TCR doté d'une affinité minimale pour les molécules du $\mathrm{CMH}$ seront préservées tandis que les cellules capables de reconnaître fortement les déterminants du soi sont physiquement éliminées (délétion clonale ou sélection négative) $[10,11]$. L'issue de l'interaction thymocyte immature/cellule stromale thymique est déterminée par la nature de son avidité, c'est-à-dire par la résultante de l'intégration de toutes les interactions moléculaires mises en jeu. L'avidité est ainsi influencée par l'affinité du TCR pour les complexes peptideCMH, par l'engagement du co-récep- 


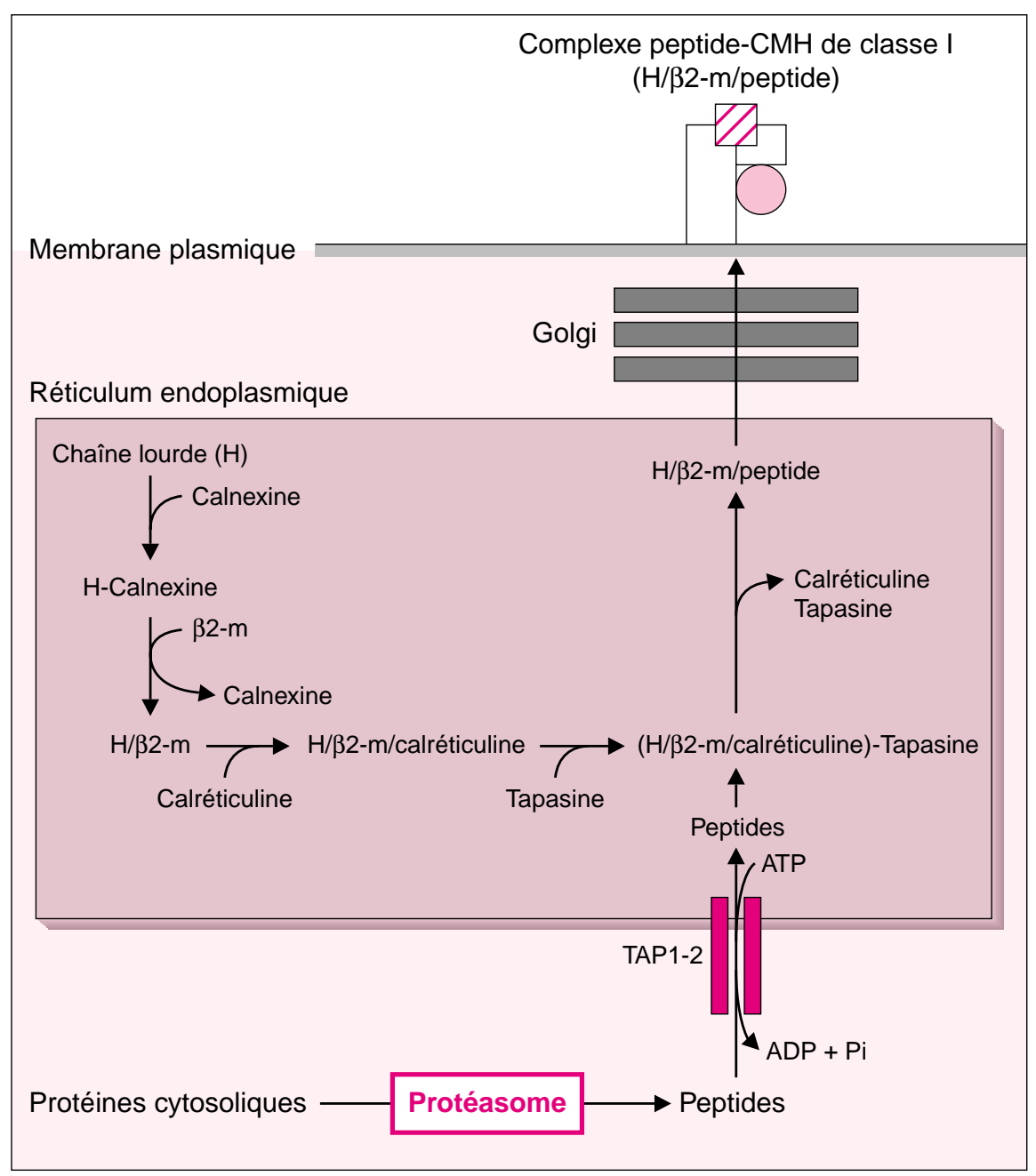

Figure 3. Représentation schématique de l'assemblage et du chargement peptidique des molécules de classe I du CMH. La chaîne lourde $(H)$ des molécules de classe I du CMH interagit successivement avec deux protéines chaperonnes qui résident dans la lumière du réticulum endoplasmique: la calnexine interagit avec la chaîne $H$ native puis la calréticuline prend le relais lorsque la chaîne lourde s'est associée à la $\beta 2$ microglobuline ( $\beta 2-m)$. La calréticuline est encore associée au complexe $H / \beta 2-m$ lorsque celui-ci s'associe au transporteur TAP grâce à une tierce protéine, la tapasine. Le chargement des peptides sur la chaîne lourde est alors possible, les trimères $H / \beta 2-m-p e p-$ tide sont libérés et transportés en surface cellulaire via I'appareil de Golgi. La majorité des peptides est engendrée dans le cytosol par le protéasome puis délivrée activement dans la lumière du réticulum endoplasmique (RE) au moyen des transporteurs TAP. Les peptides ayant les caractéristiques requises de taille et de séquence sont rapidement captés par les complexes H/B2-m. Les peptides trop longs, ainsi que des peptides dérivés de séquences signal, peuvent subirent une seconde étape de protéolyse dans le réticulum endoplasmique avant d'être éventuellement chargés sur les molécules du CMH. Une autre hypothèse considère leur exportation active vers le cytosol, un remaniement protéolytique puis un rappatriement au sein du réticulum endoplasmique via les molécules TAP. Ces possibilités restent moins bien documentées et ne sont pas représentées sur le schéma. En l'absence de $\beta 2-m$ ou de molécules TAP fonctionnelles, les molécules de classe I du $\mathrm{CMH}$ sont instables et très faiblement exprimées à la surface cellulaire. Golgi: appareil de Golgi; H: chaîne lourde des molécules de classe I du $\mathrm{CMH}$; TAP: molécules de transport; AT(D)P: adénosine tri-(bi)phosphate ; Pi: phosphate inorganique. teur CD4 ou CD8, par la densité des complexes peptide-CMH et par d'éventuelles interactions non spécifiques de nature adhérente (par exemple CD2-CD58 et/ou CD54$\mathrm{CD} 11 \mathrm{a} / \mathrm{CD} 18)$. Ce modèle de développement, le plus cohérent actuellement, est connu sous le terme de modèle de l'avidité différentielle [12]. L'absence d'une interaction TCR/ peptide-CMH significative ne permet pas aux thymocytes de s'opposer au processus de mort cellulaire génétiquement programmée (ou apoptose). La sélection positive correspond précisément à l'intégration par les thymocytes d'un signal de survie qui prévient l'apoptose. Ce scénario peut en théorie prendre place lorsque le TCR interagit faiblement avec un complexe peptide-CMH abondant ou lorsque le TCR manifeste une affinité relativement élevée pour un complexe peptide-CMH peu représenté dans l'environnement thymique. Lorsque l'avidité est très élevée ( $a$ priori cette situation correspond aux thymocytes capables de reconnaître efficacement les déterminants du soi), le signal reçu par les thymocytes active le processus apoptotique et précipite leur élimination physique. A la différence de la sélection négative relayée principalement (mais peut-être pas exclusivement) par les cellules médullaires thymiques ayant une origine hématopoiétique telles que les cellules dendritiques, de nombreuses expériences conduites in vivo (notamment au moyen d'animaux chimériques engendrés par injection de moelle osseuse après irradiation), ont démontré que la sélection positive a pour base moléculaire l'interaction du TCR avec les molécules de classe I et II du CMH exprimées par les cellules épithéliales de la zone corticale thymique [10, 12-14].

\section{Les peptides du soi et la sélection positive des lymphocytes T CD8}

Un des premiers travaux soulignant un rôle particulier des peptides du soi dans le processus de sélection positive intrathymique était fondé sur des mutations spontanées des molécules de classe I du CMH affectant l'interaction peptide-CMH sans altérer l'interaction TCR-CMH. Les résultats étaient en faveur de l'idée 


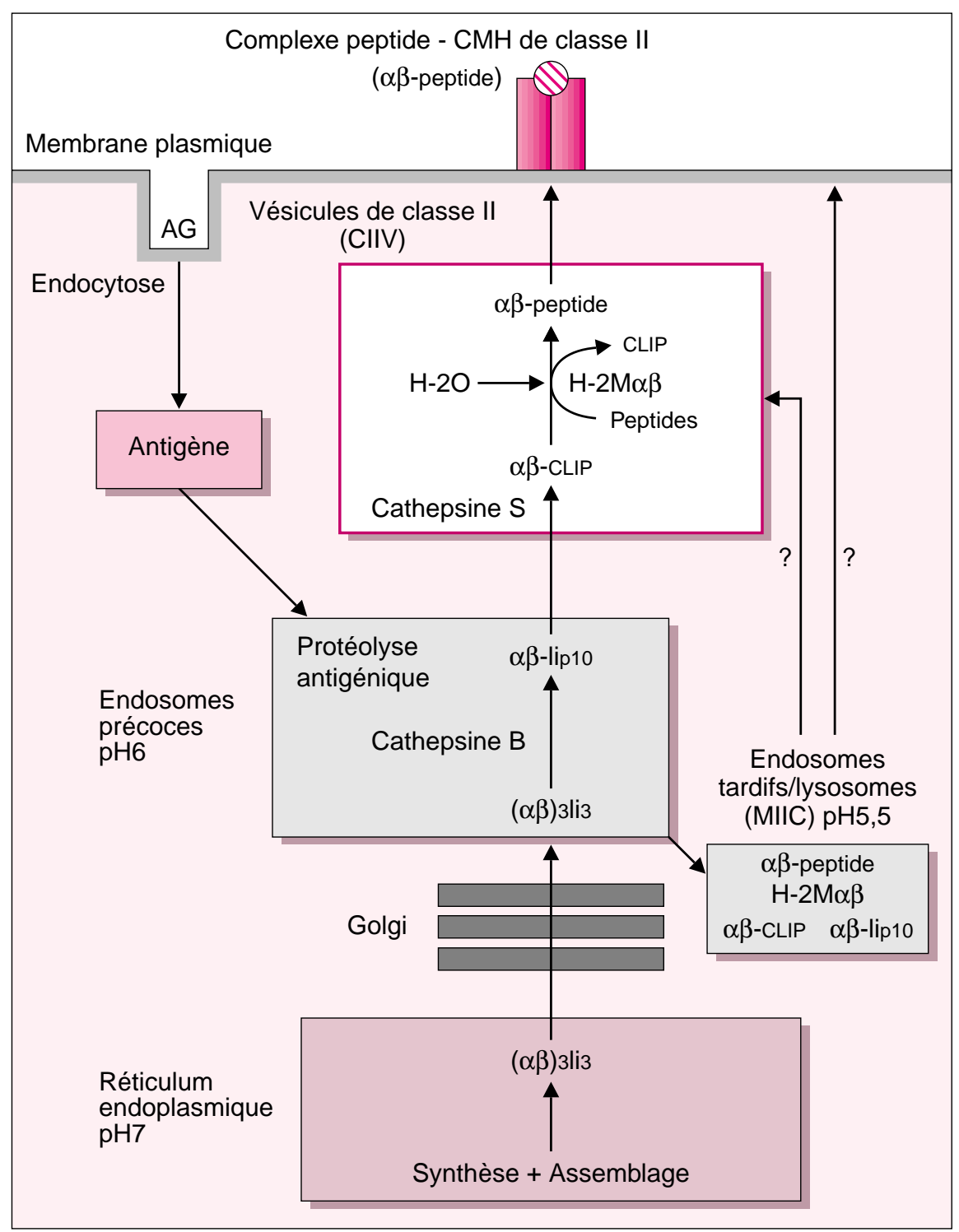

Figure 4. Représentation schématique du transport intracellulaire des molécules de classe II du CMH. Le signal de routage contenu dans la portion cytoplasmique de la chaîne invariante li oriente les complexes $(\alpha \beta)_{3} l_{3} i_{3}$ assemblés au sein du réticulum endoplasmique vers les compartiments endocytiques, notamment les endosomes précoces. li est progressivement dégradée sous I'action de protéases à cystéine (cathepsines B/S pour les cellules présentatrices de l'antigène, cathepsine $L$ pour les cellules épithéliales thymiques); I'intermédiaire li-p10 puis le peptide CLIP sont ainsi successivement engendrés. CLIP prévient l'association prématurée de fragments peptidiques. Les molécules de classe II du CMH sont très représentées au sein des endosomes tardifs et des lysosomes (compartiment MIIC). Les vésicules de classe II (CIIV) émergeraient des endosomes selon un processus de bourgeonnement. En leur sein, les peptides se substituent au peptide CLIP grâce à l'intervention des molécules $\mathrm{H}-2 \mathrm{M}$. Les complexes peptide-molécules de classe II sont ensuite dirigés vers la surface cellulaire. En l'absence de H-2M, CLIP n'est pratiquement pas déplacé et constitue le peptide dominant à la surface cellulaire. En l'absence de li, le niveau d'expression membranaire des molécules de classe II du CMH est réduit. AG: antigène; li-p10: fragment de $10 \mathrm{kDa}$ de li; CLIP: fragment de 21 acides aminés de li; $\mathrm{H}-2 \mathrm{M} \alpha \beta$ : échangeur de peptide; $\mathrm{H}-2 \mathrm{O}$ : régulateur négatif de $\mathrm{H}-2 \mathrm{M}$. selon laquelle la reconnaissance des peptides du soi participe pleinement à la sélection positive des lymphocytes $\mathrm{CD}^{+}$. Très vite, un phénomène semblable a été proposé pour les cellules $\mathrm{CD}^{+}{ }^{+}$[15-17]. D'autres résultats sont venus renforcer cette hypothèse, notamment une série d'expériences réalisées in vitro au moyen de cultures de thymus foetaux d'animaux mutants présentant une expression membranaire défectueuse des molécules de classe I du CMH. Ces mutants ont été engendrés par invalidation du gène de la $\beta 2$ - microglobuline d'une part $\left(\beta 2-m^{-/-}\right)$, du gène de la sous-unité 1 du complexe de transport des peptides $\left(T A P 1^{-/-}\right)$d'autre part (voir figure 3). Dans les deux cas, le repliement spatial et la stabilité membranaire des molécules de classe I du CMH est compromise, leur expression est sévèrement réduite et très peu de lymphocytes $\mathrm{T} \alpha \beta \mathrm{CD}^{+}$ parviennent à maturation [18, 19]. Ce déficit d'expression peut être inversé artificiellement in vitro par l'ajout de $\beta 2$-microglobuline exogène et de peptides synthétiques.

Ce système expérimental a permis deux observations majeures [12, 2021]: (1) tout peptide susceptible de s'associer aux molécules de classe I du CMH et de restaurer leur expression membranaire stable ne conduit pas nécessairement à restaurer significativement la sélection positive des lymphocytes $\mathrm{T} \mathrm{CD} 8^{+}$; (2) en considérant les peptides qui présentent un effet significatif, il a été remarqué qu'un mélange de peptides différents assure une sélection positive plus efficace que les mêmes peptides testés individuellement. Ainsi, il semble que la complexité du soi peptidique ait un impact direct sur l'efficacité du processus de sélection positive intrathymique. L'interprétation la plus satisfaisante de ce phénomène est que la reconnaissance du soi peptidique est à la base du processus de sélection positive. Des résultats cohérents avec cette idée ont été obtenus lors d'expériences identiques réalisées avec des animaux transgéniques exprimant une spécificité $\mathrm{T}$ donnée: tout peptide capable de restaurer l'expression stable des molécules de classe I du CMH ne conduit pas nécessairement à restaurer le dévelopement d'une spécificité $\mathrm{T}$ donnée. Dans ces expériences, des variants du 
peptide ont également été testés, parmi lesquels des variants agonistes ou antagonistes selon qu'ils induisent ou préviennent l'activation de lymphocytes mûrs exprimant la spécificité T en question. Il a été observé que les peptides antagonistes et les faibles concentrations de peptides agonistes peuvent restaurer la sélection positive tandis que les fortes concentrations de peptides agonistes déclenchent la sélection négative des thymocytes transgéniques [22, 23]. Dans l'ensemble, ces résultats sont cohérents avec le modèle de l'avidité différentielle. Cependant, il apparaît que la sélection positive restaurée par de faibles doses de peptides agonistes engendre des lymphocytes ayant un faible niveau d'expression du corécepteur $\mathrm{CD} 8$ et présentant des altérations fonctionnelles [24]. Cela laisse à penser que le modèle de l'avidité différentielle tel qu'il fut proposé initialement demande à être affiné. D’autres études indépendantes vont également dans ce sens $[25,26]$. Très récemment, des peptides naturellement présentés par les molécules de classe I du CMH et capables d'assurer le développement des thymocytes $\mathrm{CD}^{+}$dans des expériences de culture de thymus foetal, ont été identifiés [27, 28]. Il s'avère que de multiples peptides sont capables d'assurer le développement d'une spécificité $\mathrm{T}$ donnée et que l'homologie entre ces peptides et le peptide antigénique peut être très limitée. Ce type d'expérience se heurte toutefois à un argument d'ordre quantitatif; les quantités de peptides utilisées in vitro peuvent $\mathrm{n}$ 'avoir aucune commune mesure avec les quantités naturellement exprimées à la surface des cellules épithéliales corticales d'un thymus normal.

\section{Les peptides du soi et la sélection positive des lymphocytes T CD4+}

Les données relatives aux lymphocytes $\mathrm{CD}^{+}$sont pour l'essentiel beaucoup plus récentes et ont été obtenues in vivo, principalement par analyse d'animaux génétiquement modifiés. Ainsi, des souris exprimant un seul complexe peptide-CMH de classe II ont été engendrés (I$\left.\mathrm{A}^{\mathrm{b}}: \mathrm{E} \alpha 52-68\right)$ [29, 30] grâce à l'expres- sion in vivo d'une construction d'ADN couplant la séquence d'un peptide (E $252-68)$ à celle de l'une des chaînes des molécules de classe II du CMH (I-A $\left.A^{b} \beta\right)$. Après croisement avec des animaux mutants induits, dépourvus des molécules endogènes de classe II du CMH et de la chaîne invariante $\left(\mathrm{I}-\mathrm{A}^{\mathrm{b}-/-} / \mathrm{Ii}^{-/-}\right)$, l'expression d'un complexe peptide-CMH classe II unique est observée sur les cellules épithéliales thymiques ainsi que sur les cellules présentatrices de l'antigène. Ce complexe a été choisi entre autre parce qu'il existe un anticorps monoclonal capable de le reconnaître spécifiquement (à l'instar d'un TCR, l'anticorps monoclonal Y-A $e$ interagit à la fois avec le peptide E $\alpha 52-68$ et avec les résidus polymorphes de la molécule de classe II $\left.\mathrm{I}-\mathrm{A}^{\mathrm{b}}\right)$. Cela a permis une caractérisation fiable des animaux. L'invalidation du gène de la sous-unité $\alpha \mathrm{du}$ complexe H-2M $\alpha \beta\left(H-2 M \alpha^{-/-}\right)$a conduit à l'obtention d'animaux semblables [31-33]. Nous avons mentionné précédemment que l'hétérodimère $\mathrm{H}-2 \mathrm{M} \alpha \beta$ assure le chargement efficace des peptides dérivés des produits d'endocytose sur les molécules de classe II du CMH au sein de compartiments spécialisés (figure 4). En son absence, ce chargement est compromis et les molécules de classe II parviennent à la surface cellulaire complexées avec le fragment CLIP de la chaîne invariante. Il a été initialement proposé que les animaux $H-2 M \alpha^{-/}$constituaient un second cas de souris exprimant un seul complexe peptide-CMH classe II. En fait, le complexe peptide CLIPCMH classe II est dominant mais pas unique car il a été démontré que deux récepteurs immunitaires distincts sont capables d'interagir avec les cellules exprimant les molécules de classe II chez les mutants $H$ $2 M \alpha^{-/}$. D'une part, un hybridome $\mathrm{T}$ spécifique d'un peptide dérivé de la ß2-microglobuline présenté dans le contexte des molécules ${\mathrm{I}-\mathrm{A}^{\mathrm{b}}}^{\mathrm{es}}$ t capable de reconnaître les cellules présentatrices de l'antigène isolées a partir de la rate de mutants $H-2 M \alpha^{/-}$. D'autre part, un anticorps qui n'interagit pas avec le complexe CLIP-CMH classe II est néanmoins capable d'interférer avec le développement des thymocytes $H-2 M \alpha^{-/-}$ $\mathrm{CD}^{+}$in vitro [33]. Chez ces deux types de souris modifiées (transgénique ${\mathrm{I}-\mathrm{A}^{\mathrm{b}}}^{\mathrm{b}}$ E $\alpha 52-68$ et mutant $H$ $2 M \alpha^{-/-}$), un nombre relativement important de lymphocytes $\mathrm{CD} 4^{+}$a été détecté: environ $25 \%$ a $50 \%$ du nombre normal. Toutefois ces cellules se distinguent des lymphocytes $\mathrm{CD}^{+}$normaux par la très vive réactivité que la plupart d'entre eux sont capable de manifester vis-à-vis de cellules présentatrices de l'antigène syngénique, c'est-à-dire vis-à-vis de complexes peptide-CMH classe II porteurs d'un répertoire peptidique normal. La plupart de ces cellules $\mathrm{CD}^{+}$ne peuvent donc pas être assimilées aux lymphocytes CD4 ${ }^{+}$qui se développent au sein du thymus de souris génétiquement non manipulées. Par ailleurs, des résultats obtenus par transfert de moelle osseuse, ou tout simplement par croisement, ont révélé que l'environnement thymique des animaux $\mathrm{H}-2 \mathrm{M}^{-/}$est incapable d'assurer le développement de lymphocytes $\mathrm{T}$ transgéniques exprimant des spécificités restreintes par les molécules CMH de classe II [3436]. En d'autres termes, des lymphocytes porteurs de spécificités données qui ont pu se développer au sein d'un thymus normal (c'est-à-dire qui ont été séléctionnés positivement), ne peuvent parvenir à maturité lorsqu'ils sont confrontés à une diversité du soi très sévèrement réduite. Ces observations indiquent clairement que la sélection positive des thymocytes $\mathrm{CD}^{+}$est dépendante des peptides du soi. Il est important de préciser que le niveau d'expression des molécules de classe II du $\mathrm{CMH}$ des mutants $H-2 M \alpha^{-1}$ est identique à celui d'une souris normale. Cela a été confirmé par immunomarquage à l'aide d'un anticorps monoclonal anti-CMH de classe II (Y3JP) dont la réactivité est indépendante des caractéristiques des peptides associés (ce n'est pas complètement vrai pour les animaux I-A ${ }^{\mathrm{b}}$ : E $\alpha 52-68$ chez lesquels le niveau d'expression des molécules de classe II du CMH est sensiblement réduit). Cela permet de conclure que chez les mutants $H-2 M \alpha^{-/}$, les effets observés sont bien liés à la diversité restreinte du répertoire peptidique et non à une expression modifiée des molécules de classe II du CMH.

Les animaux chez lesquels la chaîne invariante est absente $\left(\mathrm{Ii}^{-/-}\right)$sont également présumés porteurs d'un soi 
peptidique restreint; les molécules de classe II du CMH sont très faciles à charger de façon exogène, ce qui suggère que les peptides associés ont une faible affinité pour les molécules de classe II [37]. Chez ces animaux, la sélection positive de thymocytes transgéniques $\mathrm{CD}^{+}$semble également être compromise (4 TCR parmis 5 testés) [34, 38]. Il faut mentionner que ces mutants ont un taux d'expression des molécules de classe II réduit et il est théoriquement possible que ce paramètre ait un rôle dans la sélection positive altérée des spécificités $\mathrm{T}$ testées. Les animaux transgéniques I-A ${ }^{\mathrm{b}}$ : E $\alpha 52-68$ présentent aussi cette caractéristique car ils sont également dépourvus de Ii. Cette condition est nécessaire pour prévenir le déplacement du peptide E $\alpha 52-68$ par des peptides endogènes. Cependant, la reconstitution chez les souris $\mathrm{Ii}^{-/-}$, d'un faible niveau d'expression de deux des isoformes de la chaîne invariante (p31 et p41) au moyen de transgènes, a révélé que la sélection positive des thymocytes $\mathrm{CD}^{+}$peut être restaurée sans que le taux d'expression des molécules de classe II ne soit modifié [39]. Cela suggère que chez ces mutants, indépendamment du taux d'expression des molécules de classe II, c'est l'absence de chaîne invariante et ses effets sur le répertoire peptidique qui sont responsables des anomalies de la sélection positive des lymphocytes $\mathrm{T}$ $\mathrm{CD} 4^{+}$.

Le rôle des peptides du soi dans la sélection positive est également confirmé par quatre autres études indépendantes conduites in vivo.

1. L'analyse de souris transgéniques exprimant uniquement la chaîne $\beta$ d'un TCR donné a révélé que, parmi les chaînes $\alpha$ utilisant les segments $\mathrm{V}$ et J parentaux, la fréquence de la séquence CDR3 $\alpha$ du clone parental est basse au sein des thymocytes ayant une expression faible du TCR, mais haute au sein de la population thymocytaire ayant une expression élevée du TCR (c'est-à-dire faible préalablement, mais élevée postérieurement à l'étape de sélection positive). Étant donné que, lors de l'interaction TCRpeptide-CMH, le segment CDR3 $\alpha$ correspond à une boucle qui est un point de contact direct entre la chaîne $\alpha$ du TCR et le peptide, ce résultat indique

dans la sélection positive [40]. Un phénomène semblable a été observé chez des animaux transgéniques I$\mathrm{A}^{\mathrm{b}}:$ E $\alpha 52-68$ porteurs d'un transgène codant pour la chaîne $\beta$ d'un TCR [41].

2. L'analyse de souris mutantes a révélé que la dégradation de la chaîne invariante dans les lysosomes des cellules épithéliales corticales thymiques est controlée par la cathepsine L. Dans le cas des cellules présentatrices de l'antigène, cette fonction est assurée par d'autres protéinases de la même famille (figure 4). Par conséquent, chez les animaux cathepsine $L^{-/}$, les cellules assurant la sélection positive expriment des molécules de classe II du CMH porteuses principalement de produits de la dégradation incomplète de la chaîne invariante. Ces animaux constituent un autre exemple de soi peptidique restreint. Leur analyse a révélé que la sélection positive des thymocytes $\mathrm{CD}^{+}$est clairement défectueuse; peu de lymphocytes $\mathrm{T}$ $\mathrm{CD}^{+}$sont détectés au sein du thymus ainsi qu'en périphérie (la réduction est de l'ordre de $60 \%$ a $80 \%$ ) [42]. Les lymphocytes $\mathrm{T} \mathrm{CD}^{+}$résiduels apparaissent normaux et ne manifestent pas de réactivité vis-à-vis de cellules présentatrices de l'antigène d'origine syngénique. Cela n'est pas surprenant puisque, chez ces animaux, la sélection négative n'est pas altérée; les cellules exprimant des molécules de classe II du CMH, dérivées de la moelle osseuse, assurent une dégradation normale de la chaîne invariante (dans ces cellules, la dégradation de Ii n'implique pas la cathepsine L mais plutot la cathepsine S) et expriment un soi peptidique normal.

3. Des souris chez lesquelles $95 \%$ des molécules de classe II du CMH présentent un peptide unique ont un nombre normal de lymphocytes $\mathrm{CD}^{+}$. Cependant, si la diversité du soi peptidique est davantage restreinte $(<5 \%)$, le développement des lymphocytes $\mathrm{CD} 4^{+}$est altéré. Cela montre que la diversité du soi peptidique, et par conséquent la reconnaissance des peptides, à un effet direct sur la maturation des thymocytes [43].

4. Un anticorps monoclonal spécifique d'un complexe peptide-CMH classe II donné est capable d'interfé- rer in vivo avec la sélection positive de thymocytes transgéniques exprimant un TCR spécifique pour ce même complexe. Le fait que cet anticorps soit très sensible à des mutations introduites dans le peptide suggère que les peptides endogènes participant à la sélection positive d'une spécificité $\mathrm{T}$ donnée et le peptide reconnu par des lymphocytes $T$ mûrs porteurs de cette spécificité peuvent avoir des caractéristiques structurales relativement proches [44].

\section{Conclusions}

Nous venons de voir qu'il existe maintenant une base expérimentale solide et généralisée étayant la notion selon laquelle la sélection positive des thymocytes immatures (c'est-à-dire l'élaboration du répertoire lymphocytaire $\mathrm{T}$ mûr) est un processus ayant pour base moléculaire la reconnaissance des peptides du soi par le récepteur de l'antigène. Une série de travaux récents indique par ailleurs que le répertoire $\mathrm{T} n$ 'est pas définitivement établi à l'issue du processus de développement intrathymique. Ainsi, il semble maintenant bien établi qu'une interaction TCR-CMH régulière est requise pour le maintien physique des lymphocytes $\mathrm{T} \alpha \beta$ en périphérie. Par exemple, le transfert adoptif de lymphocytes $\mathrm{CD}^{+}$naïs chez différents types de receveurs a permis de montrer que la persistance de ces cellules nécessite l'expression de l'élément CMH de restriction chez le receveur. De même, la greffe de thymus foetal chez des receveurs déficients en molécules RAG ou doublement déficients en molécules RAG et en molécules de classe II du CMH a révélé que les lymphocytes $\mathrm{T} \mathrm{CD}^{+}$naïfs nouvellement produits chez le receveur disparaissent en l'absence d'expression membranaire de molécules de classe II du CMH. Un système expérimental très différent $a$ conduit à la même conclusion. L'introduction d'un gène in situ au moyen d'un vecteur viral permettant la restauration transitoire des molécules de classe II du CMH par l'épithélium thymique peut reconstituer la sélection positive et l'exportation en périphérie des lymphocytes $\mathrm{CD} 4^{+}$. Cependant, à long terme, ces cellules 
disparaissent. L'ensemble de ces résultats est compatible avec l'idée selon laquelle le maintien des lymphocytes $\mathrm{T} \alpha \beta$ périphériques (et par conséquent, de la diversité du répertoire $\mathrm{T}$ périphérique) dépend d'un signal de survie (ou anti-apoptotique) délivré lors d'interactions TCR-CMH de faible affinité survenant par exemple lors des contacts fréquents et très étroits que les lymphocytes T entretiennent avec les cellules dendritiques au sein des organes lymphoïdes secondaires. Ce modèle est remarquablement évocateur du processus de sélection positive intrathymique et suggère la notion de «sélection positive périphérique" des lymphocytes $\mathrm{T} \alpha \beta$. Tenter d'établir un parallèle de ce type conduit tout naturellement à soulever une autre question; les peptides du soi ont-ils, dans l'interaction TCR-CMH assurant la survie lymphocytaire $\mathrm{T}$ périphérique, un rôle aussi fondamental que celui qu'ils remplissent dans l'élaboration du répertoire $\mathrm{T}$ au travers du processus de sélection positive intrathymique? Enfin, on peut se demander si le fait que le répertoire $\mathrm{T}$ soit forgé par une reconnaissance du soi peptidique n'est pas une explication plausible à l'influence que les éléments du CMH peuvent excercer sur la susceptibilité aux maladies auto-immunes spécifiques

\section{RÉFÉRENCES}

1. Sigaux F. Physiologie et pathologie de la recombinaison V(D) J. Med Sci 1994; 10 : 995-1005.

2. Zinkernagel RM. Lecture for the Nobel Prize for physiology or medicine. Cellular immune recognition and the biological role of major transplantation antigens. Scand J Immunol 1997; 46 : 421-36.

3. Lotteau V. Protéasome et présentation de l'antigène. Med Sci 1993; 9: 1284-5.

4. Pamer E, Cresswell P. Mechanisms of MHC class I-restricted antigen processing. Annu Rev Immunol 1998; 16:323-58.

5. Wolf PR, Ploegh HL. How MHC class II molecules acquire peptide cargo: Biosynthesis and trafficking through the endocytic pathway. Ann Rev Immunol 1995; 11 : 267-306.

6. Amigorena S. Transport intracellulaire des molécules de classe II du CMH. Med Sci $1995 ; 11: 66-8$.

$\mathrm{m} / \mathrm{s} n^{\circ} 12$, vol. 15 , décembre 99
7. Cresswell P. Invariant chain structure and MHC class II function. Cell 1996; 23; 84 : 505-7.

8. Groettrup M, von Boehmer H. A role for a pre-T cell receptor in $\mathrm{T}$ cell development. Immunol Today 1993; 14: 610-4.

9. Fehling HJ, von Boehmer H. Early $\alpha \beta \mathrm{T}$ cell development in the thymus of normal and genetically altered mice. Cur Op Immunol 1997; 9 : 263-75.

10. Robey E, Fowlkes BJ. Selective events in T cell development. Ann Rev Immunol 1994; 12: 675-705.

11. Nossal GJV. Negative selection of lymphocytes. Cell 1994; 76 : 229-40.

12. Jameson SC, Hogquist K.A, Bevan MJ. Positive selection of thymocytes. Ann Rev Immunol 1995; 13: 93-126.

13. Janeway CA Jr. Thymic selection: two pathways to life and two to death. Immunity $1994 ; 1: 3-6$.

14. von Boehmer H. Positive selection of lymphocytes. Cell 1994; 76 : 219-28.

15. Nikolic-Zugic J, Bevan MJ. Role of selfpetides in positively selecting the $\mathrm{T}$ cell receptor repertoire. Nature $1990 ; 344$ : 65-7.

16. Sha WC, Nelson CA, Newberry RD, et al. Positive selection of transgenic receptor-bearing thymocytes by $\mathrm{K}^{\mathrm{b}}$ antigen is altered by $\mathrm{K}^{\mathrm{b}}$ mutations that involve peptide binding. Proc Natl Acad Sci USA 1990; 87: 6186-90.

17. Berg LJ, Frank GD, Davis MM. The effects of MHC gene dosage and allelic variation on $\mathrm{T}$ cell receptor selection. Cell $1990 ; 60: 1043-53$.

18. Zijlstra M, Bix M, Simister M.E, Loring JM, Raulet DH, Jaenish R. $\beta 2$-microglobulin deficient mice lack CD4-CD8 ${ }^{+}$cytolytic $\mathrm{T}$ cells. Nature 1990; 344: 742-6.

19. Van Kaer L, Ashton-Rickardt PG, Ploegh HL, Tonegawa S. TAP1 mutant mice are deficient in antigen presentation, surface class I molecules, and CD4-8 ${ }^{+} \mathrm{T}$ cells. Cell 1992; 71 : 1205-14.

20. Hogquist KA, Gavin MA, Bevan MJ. Positive selection of $\mathrm{CD}^{+} \mathrm{T}$ cells induced by major histocompatibility complex binding peptides in fetal thymic organ culture. JExp Med 1993; 177: 1469-73.

21. Asthon-Rickardt PG, Van Kaer L, Schumacher TNM, Ploegh HL, Tonegawa S. Peptide contributes to the specificity of positive selection of $\mathrm{CD}^{+} \mathrm{T}$ cells in the thymus. Cell 1993; 73 : 1041-9.

22. Hogquist KA, Jameson SC, Heath WR, Howard JL, Bevan MJ, Carbone FR. T cell receptor antagonist peptides induce positive selection. Cell 1994; 76 : 17-27.

23. Ashton-Rickardt PG, Bandeira A, Delaney JR, et al. Evidence for a differential avidity model of $\mathrm{T}$ cell selection in the thymus. Cell 1994; 76: 651-63.
24. Hogquist KA, Jameson SC, Bevan MJ. Strong agonist ligands for the T cell receptor do not mediate positive selection of functional $\mathrm{CD}^{+} \mathrm{T}$ cells. Immunity 1995; 3 : 79-86.

25. Girao C, Hu O, Sun J, Ashton-Rickardt PG. Limits to the differential affinity model of $\mathrm{T}$ cell selection in the thymus. J Immunol 1997; 159: 4205-11.

26. Cook JR, Wormstall EM, Hornell T, Russell J, Connolly JM, Hansen TH. Quantitation of the cell surface level of $\mathrm{L}^{\mathrm{d}}$ resulting in positive versus negative selection of the $2 \mathrm{C}$ transgenic $\mathrm{T}$ cell receptor in vivo. Immunity 1997; 7 : 233-41.

27. Hogquist K.A, Tomlinson AJ, Kieper WC, et al. Identification of a naturally occuring ligand for thymic positive selection. Immunity 1997; 6 : 389-99.

28. Hu Q, Walker CRB, Girao C, et al. Specific recognition of thymic self-peptides induces the positive selection of cytotoxic T lymphocytes. Immunity 1997; 7: 221-31.

29. Igantowicz L, Kappler J, Marrack P. The repertoire of $\mathrm{T}$ cells shaped by a single MHC/peptide ligand. Cell 1996; 84 : 521-9.

30. Fukui $\mathrm{Y}$, Ishimoto $\mathrm{T}$, Utsuyama M, et al. Positive and negative CD $4^{+}$thymocyte selection by a single MHC class II/peptide ligand affected by its expression level in the thymus. Immunity 1997; 6: 401-10.

31. Fung-Leung WP, Surh CD, Liljedahl M, et al. Antigen presentation and T cell development in H2-M deficient mice. Science 1996 ; 271 : 1278-81.

32. Martin WD, Hicks GG, Mendiratta SK, Leva HI, Ruley EH, Van Kaer L. H-2M mutant mice are defective in the peptide loading of class II molecules, antigen presentation, and $\mathrm{T}$ cell repertoir selection. Cell 1996; 84 : 543-50.

33. Miyazaki T, Wolf $\mathrm{P}$, Tourne $\mathrm{S}$, et al. Mice lacking H2-M complexes, enigmatic elements of the MHC class II pepting loading pathway. Cell 1996; 84: 531-41.

34. Grubin CE, Kovats S, deRoos P, Rudensky AY. Deficient positive selection of $\mathrm{CD} 4^{+} \mathrm{T}$ cells in mice displaying altered repertoire of MHC class II bound self-peptides. Immunity 1997; 7 : 197-208.

35. Tourne S, Miyazaki T, Oxenius A, et al. Selection of a broad repertoire of $\mathrm{CD}^{+} \mathrm{T}$ cells in mice $\mathrm{H}-2 \mathrm{Mao} / \mathrm{o}$ mice. Immunity 1997; 7 : 187-96.

36. Surh CD, Lee DS, Fung-Leung WP, Karlsson L, Sprent J. Thymic selection by a single MHC/peptide ligand produces a semi-diverse repertoire of $\mathrm{CD} 4^{+} \mathrm{T}$ cells. Immunity 1997; 7: 209-19.

37. Bikoff EK, Huang LY, Episkopou V, van Meerwijk J, Germain RN, Robertson EJ. Defective MHC complex class II assembly, transport, peptide acquisition and $\mathrm{CD} 4^{+} \mathrm{T}$ cell selection in mice lacking invariant chain expression. J Exp Med 1993; 177 : 1699-712. 


\section{RÉFÉRENCES}

38. Tourne S, Nakano N, Viville S, Benoist C, Mathis D. The influence of invariant chain on the positive selection of single $\mathrm{T}$ cell receptor specificities. Eur J Immunol 1995; 25 : 1851-6.

39. Naujokas MF, Arneson LS, Fineschi B, et al. Potent effects of low levels of MHC class II associated invariant chain on $\mathrm{CD} 4^{+} \mathrm{T}$ cell development. Immunity 1995; 3 : 359-72.

40. Sant'Angelo DB, Waterbury PG, Cohen $\mathrm{BE}$, et al. The imprint of intrathymic selfpeptides on the mature $\mathrm{T}$ cell receptor repertoire. Immunity 1997; 7: 517-24.

41. Fukui Y, Hashimoto O, Inayoshi A, et al. Highly restricted $\mathrm{T}$ cell repertoire shaped by a single major histcompatibility complexpeptide ligand in the presence of a single rearranged $\mathrm{T}$ cell receptor $\beta$ chain. $J$ Exp Med 1998; 188: 897-907.

42. Nakagawa $\mathrm{T}$, Roth $\mathrm{W}$, Wong $\mathrm{P}$, et al. Cathepsin L: critical role in Ii degradation and $\mathrm{CD} 4 \mathrm{~T}$ cell selection in the thymus. Science 1998 ; 280 : 450-3.

43. Barton GM, Rudensky AY. Requirement for diverse, low-abundance peptides in positive selection of T cells. Science 1999; 283: 67-70.

44. Baldwin KK, Reay PA, Wu L, Farr A, Davis MM. A T cell receptor-specific blockade of positive selection. JExp Med 1999; 189: 13-24.

\section{TIRÉS À PART}

C. Viret.

\section{Summary}

The role of self-peptides in intrathymic

$T$ cell positive selection

The generation of mature $\alpha \beta \mathrm{T}$ cells is directly dependent on molecular interactions between the TCR and the MHC interaction during intrathymic development. Pioneering experiments using mice bearing spontaneous MHC class I molecules mutations, which affect peptide binding but not the TCR/MHC interaction, have suggested an important role for selfpeptides in the development of mature $\mathrm{CD}^{+} \mathrm{T}$ lymphocytes. This idea received considerable support when mice deficient for MHC class I molecules were used: fetal thymic organ culture experiments demonstrated that all the peptides able to restore surface expression of MHC class I molecules do not necessarily restore the development of $\mathrm{CD}^{+}$thymocytes. Additionally, a mixture of different peptides was found to be more efficient than individual peptides in driving positive selection, suggesting that self complexity controls optimal $\mathrm{T}$ cell positive selection. Recent in vivo observations obtained with genetically modified mice indicate that this notion also applies to the development of $\mathrm{CD} 4^{+}$thymocytes. For instance, normal expression of MHC class II molecules, which display a very restricted set of selfpeptide on thymic epithelium, leads to a deficient positive selection of $\mathrm{CD}^{+} \mathrm{T}$ cells. Altogether, these in vitro and in vivo observations strongly indicate that the process of positive selection of immature thymocytes, and therefore the shaping of the mature TCR repertoire, is self-peptide specific. 